\title{
Anemia hemolítica inmunomediada de origen vírico en una yegua: estudio de caso
}

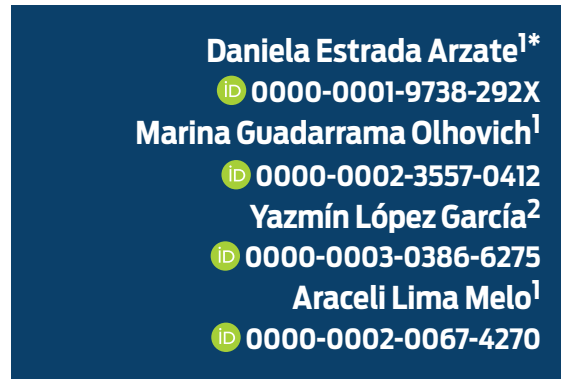

'Patología Clínica, Departamento de Patología, Facultad de Medicina Veterinaria y Zootecnia Universidad Nacional Autónoma de México. Ciudad Universitaria 3000 , Col. Copilco Universidad, Delegación Coyoacán, Ciudad de México, CP. 04360.

${ }^{2}$ Hospital para Équidos, Departamento de Medicina, Cirugía yZootecnia para Équidos,

Facultad de Medicina Veterinaria y Zootecnia,

Universidad Nacional Autónoma de México. Ciudad Universitaria 3000 , Col. Copilco Universidad, Delegación Coyoacán, Ciudad de México, CP. 04360.

* Autor para correspondencia: Correo electrónico: estrada.arzate24@gmail.com

Ponencia: caso expuesto en el $11^{\circ}$ Congreso Latinoamericano de Patología Clínica Veterinaria (octubre 2018)

Recibido: 2019-06-20 Aceptado: 2019-08-19 Publicado: $2019-09-20$

Información y declaraciones adicionales en la página 9

(a) Derechos de autor: Daniela Estrada Arzate et al. 2019

acceso abierto $\boldsymbol{O}$

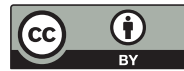

Distribuido bajo una Licencia Creative Commons Atribución 4.0 Internacional (CC-BY 4.0)

\section{Resumen}

Descripción del caso: yegua cuarto de milla de seis años de edad que no pudo desempeñarse como corredora porque estuvo deprimida y con hiporexia desde que fue adquirida.

Hallazgos clínicos: taquicardia, taquipnea, fiebre, mucosas pálidas, linfadenomegalia mandibular, apariencia delgada y signos de laminitis. Las pruebas rápidas revelaron anemia severa e hiperproteinemia.

Tratamiento y evolución: se mantuvo con terapia de líquidos, flunixin de meglumine, ranitidina y cisaprida. La paciente mantuvo todos los signos clínicos, excepto la hiporexia, pues a partir del día dos, mejoró su apetito.

Pruebas de laboratorio: se realizaron estudios el día 1 y 4, los cambios relevantes fueron anemia severa de origen hemolítico inmunomediado, reticulocitos de $1.2 \%$, incremento en el volumen globular medio (VGM) y el índice de distribución eritrocitaria (RDW), inflamación crónica severa, hiperbilirrubinemia por lisis eritrocitaria y acidosis metabólica por acumulación de ácidos. El día 4 tuvo daño hepatocelular severo y probable colestasis. En la inmunodifusión en agar gel realizada el día 2 , se obtuvo resultado positivo para anemia infecciosa equina.

Relevancia clínica: la anemia infecciosa equina es una de las principales causas de anemia hemolítica inmunomediada en esta especie. A pesar de que se consideran ausentes en equinos, se observaron reticulocitos en el frotis
Una forma de citar este artículo:

Estrada-Arzate D, Guadarrama-Olhovich M, López-García Y, Lima-Melo A. Anemia hemolítica inmunomediada de origen vírico en una yegua: estudio de caso. Clínica veterinaria: abordaje diagnóstico y terapéutico. 2019;e39201958. doi: https://doi. org/10.22201/fmvz.23958766e.201946 
teñido con nuevo azul de metileno. Debido a que el medio para confirmar un proceso regenerativo en caballos es el análisis de médula ósea, se ha recurrido al estudio de otros índices en el hemograma, tales como el VGM y el RDW.

Palabras clave: hemograma, regeneración, reticulocitos, índices eritrocitarios, anemia hemolítica.

\section{Immune-mediated hemolytic anemia of viral origin in a mare: a case study}

\section{Abstract}

Case description: six year-old quarter mile mare that could not perform as a racehorse due to depression and hyporexia since she was acquired.

Clinical findings: tachycardia, tachypnea, fever, pale mucous membranes, lymphadeno megalia mandibular, slim appearance and signs of laminitis. Rapid tests revealed severe anemia and hyperproteinemia.

Lab test: laboratory studies were made on days 1 and 4 , the outstanding changes were severe anemia of immune-mediated origin, $1.2 \%$ of reticulocytes, mean cell volume (MCV) increase, red cell distribution width (RDW) increase, severe chronic inflammation, hyperbilirubinemia due to erythrocyte lysis, and high anion gap metabolic acidosis. On day 4, it had severe hepatocellular damage and potential cholestasis. The agar gel immunodiffusion test made on day 2 , had a positive result for equine infectious anemia.

Treatment and evolution: she was administered fluid therapy, flunixin meglumine, ranitidine, and cisapride. All clinical signs remained, except for hyporexia, since its apetite improved from day two.

Clinical relevance: equine infectious anemia is one of the main causes of immune-mediated hemolytic anemia in this species. Despite the fact that reticulocytes are considered absent in horses, we observed them on a blood smear stained with new methylene blue. Because bone marrow analysis is needed to confirm a regenerative process in horses, other erythrocyte indices have been studied, such as MCV and RDW.

Keywords: complete blood count, regeneration, reticulocytes, erythrocyte indices, hemolytic anemia, mare. 


\section{Descripción del caso}

Se presentó al Hospital de Équidos de la Facultad de Medicina Veterinaria y Zootecnia de la Universidad Nacional Autónoma de México, una yegua, cuarto de milla, hembra, de seis años y $418 \mathrm{~kg}$ (Figura 1), proveniente de Michoacán (México). El dueño refirió que fue adquirida dos meses antes en Estados Unidos de América para desempeñarse como corredora, pero no lo logró porque siempre estuvo deprimida y con hiporexia.

\section{Hallazgos clínicos e interpretación}

El día de su llegada (día 1), en el examen físico se apreció taquicardia de $80 / \mathrm{min}$ (28-40/min), taquipnea de $32 / \mathrm{min}(8-16 / \mathrm{min})$, fiebre de $38.4^{\circ} \mathrm{C}\left(37.2-38^{\circ} \mathrm{C}\right)$, mucosas pálidas, linfadenomegalia mandibular y apariencia delgada. Se detectó incremento en la temperatura de los cascos de los miembros torácicos y pulso digital positivo (hallazgos compatibles con laminitis).

Se realizaron pruebas rápidas, como determinación del hematocrito y sólidos totales, en las que se obtuvo de $0.17 \mathrm{~L} / \mathrm{L}(0.32-0.52 \mathrm{~L} / \mathrm{L})$ y $87 \mathrm{~g} / \mathrm{L}(60-80 \mathrm{~g} / \mathrm{L})$ respectivamente, lo que indicó anemia severa e hiperproteinemia. Por los hallazgos anteriores, esta yegua fue hospitalizada.

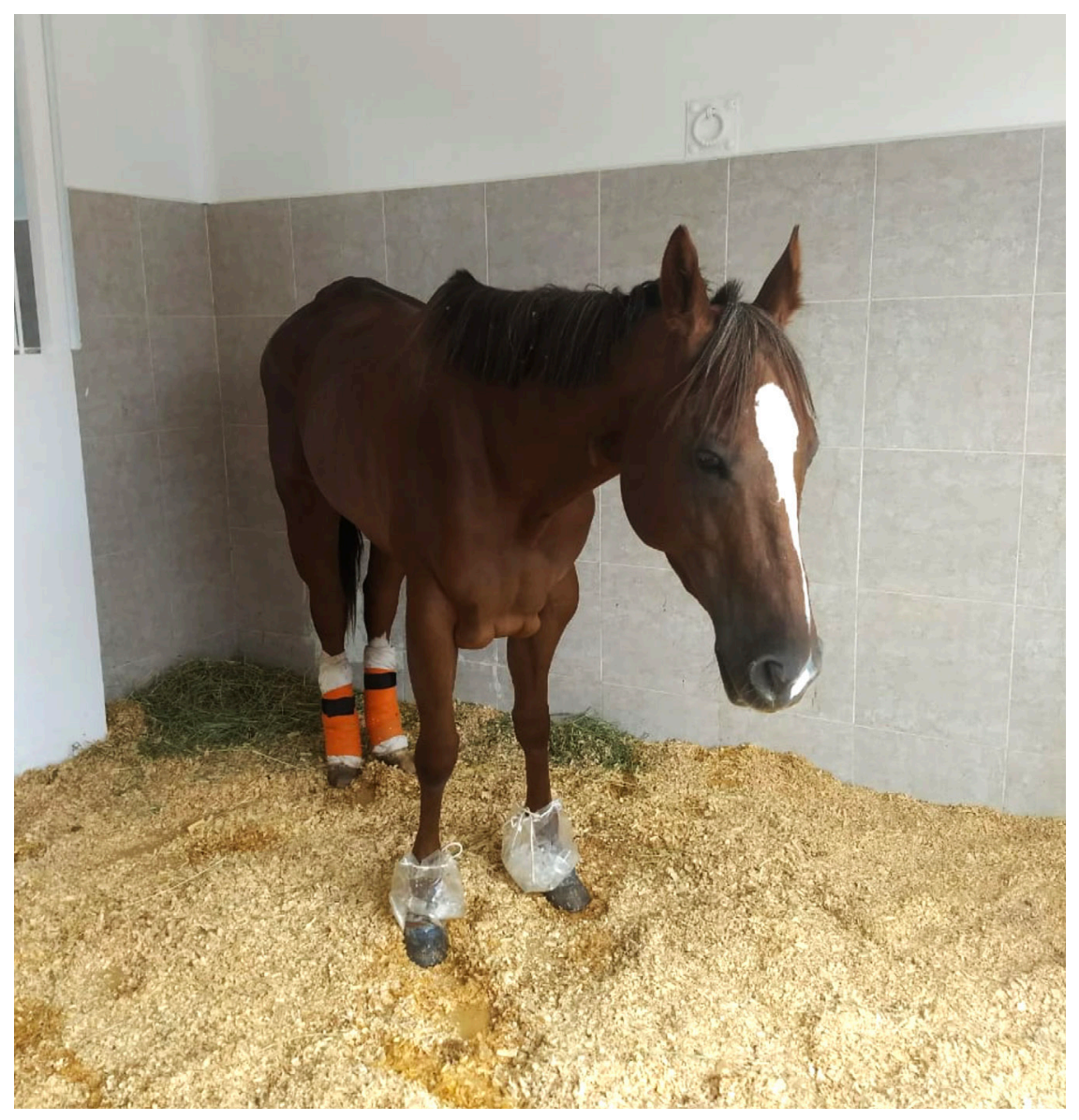

Figura 1. Aspecto y condición de la yegua cuarto de milla. 
Cuadro 1. Resultado de hemogramas de la yegua cuarto de milla.

\begin{tabular}{|c|c|c|c|c|c|c|}
\hline & Día 1 & Día 4 & & & Día 1 & Día 4 \\
\hline Mesurando & \multicolumn{2}{|c|}{ Valor } & Referencia & Unidad & \multicolumn{2}{|c|}{ Morfología } \\
\hline Hematocrito & 0.15 & 0.13 & $0.32-0.52$ & $\mathrm{~L} / \mathrm{L}$ & \multirow{8}{*}{$\begin{array}{l}\text { Anisocitosis } 2+ \\
\text { RDW } 25 \% \\
(16-21 \%) \\
\text { Aglutinación (+) } \\
\text { E. nucleados } 5 / 100 \text { L } \\
\text { N. tóxicos } 2+ \\
\text { Linfocitos reactivos 1+ }\end{array}$} & \multirow{8}{*}{$\begin{array}{l}\text { Anisocitosis 2+ } \\
\text { RDW } 24 \% \\
(16-21 \%) \\
\text { Aglutinación (+) } \\
\text { E. nucleados } \\
10 / 100 \text { L } \\
\text { N. tóxicos } 1+ \\
\text { Remanentes } \\
\text { nucleares } 1+ \\
\text { Reticulocitos } 1.2 \%\end{array}$} \\
\hline Hemoglobina & 59 & 49 & $111-190$ & $\mathrm{~g} / \mathrm{L}$ & & \\
\hline Eritrocitos & 2.1 & 1.5 & $6.5-12.5$ & $\times 10^{12} / \mathrm{L}$ & & \\
\hline VGM & 71 & 87 & $34-58$ & $f L$ & & \\
\hline CGMH & 393 & 377 & $310-370$ & $g / L$ & & \\
\hline Plaquetas & Suficientes & 188 & $100-600$ & $\times 10^{9} / \mathrm{L}$ & & \\
\hline Sólidos totales & 83 & 84 & $60-80$ & $g / L$ & & \\
\hline Fibrinógeno & 2 & 3 & $2-4$ & $g / L$ & & \\
\hline Leucocitos & 6.4 corregido & 10 corregido & $5.5-12.5$ & $\times 10^{9} / \mathrm{L}$ & \multicolumn{2}{|c|}{ Otros hallazgos } \\
\hline Neutrófilos & 1.7 & 3.8 & $2.7-6.7$ & $\times 10^{9} / \mathrm{L}$ & \multirow{4}{*}{$\begin{array}{l}\text { Hemólisis } 1+ \\
\text { Lipemia } 2+ \\
\text { Rel. ST/Fb }=41(>20) \\
\text { Agregados plaquetarios 2+ }\end{array}$} & \multirow{3}{*}{$\begin{array}{l}\text { Lipemia 3+ } \\
\text { Îndice ictérico } \\
\text { incrementado }\end{array}$} \\
\hline Bandas & 0 & 0.1 & 0 & $\times 10^{9} / \mathrm{L}$ & & \\
\hline Linfocitos & 3.3 & 5.1 & $1.5-7.5$ & $\times 10^{9} / \mathrm{L}$ & & \\
\hline Monocitos & 1.4 & 1 & $0-0.8$ & $\times 10^{9} / \mathrm{L}$ & & $\begin{array}{l}\text { Rel. ST/Fb=27 } \\
(>20)\end{array}$ \\
\hline
\end{tabular}

\section{Tratamiento y evolución}

Se administró terapia de líquidos glucosada (2 L cada hora), adicionada con aminoácidos (solo durante el primer día), flunixin de meglumine (1.1 mg/kg IV BID), ranitidina ( $1.5 \mathrm{mg} / \mathrm{kg}$ IV TID), cisaprida (0.1 mg/kg PO BID), pentoxifilina ( $8.5 \mathrm{mg} / \mathrm{kg}$ PO BID) y se aplicó hielo en los miembros torácicos, así como vendas de descanso.

Del día 1 al 4, la paciente se mantuvo con mucosas pálidas, taquicardia y taquipnea en las que las frecuencias variaron entre $77 /$ min a $100 /$ min y entre 20/min a 40/min, respectivamente. De igual manera estos días continuó con pulso digital positivo. Hasta el día 3 la paciente presentó fiebre, que fluctuó entre $38.2^{\circ} \mathrm{C}$ y $39.9^{\circ} \mathrm{C}$

A partir del día 2 de hospitalización, la evolución de la paciente fue favorable en cuanto al apetito.

\section{Pruebas de laboratorio}

El día 1 se realizaron hemograma, bioquímica sérica y urianálisis (Cuadros 1-3) en el Laboratorio de Patología Clínica del Departamento de Patología de la Facultad de Medicina Veterinaria y Zootecnia de la Universidad Nacional Autónoma de México, el resultado fue anemia severa, que debido a la aglutinación, se diagnosticó como hemolítica inmunomediada. Asimismo, por el incremento de sólidos totales, neutropenia y monocitosis, se confirmó una inflamación crónica severa.

En la bioquímica presentó hiperglucemia relacionada con el incremento en su aporte (terapia de líquidos glucosada), hiperazotemia prerrenal e hiperfosforemia por disminución en la tasa de filtrado glomerular por hemoconcentración; hiperbilirrubinemia por hiporexia y por la lisis eritrocitaria inmunomediada; 
Cuadro 2. Resultado de bioquímicas séricas de la yegua cuarto de milla.

\begin{tabular}{|c|c|c|c|c|}
\hline & Día 1 & Dfa 4 & & \\
\hline Mesurando & \multicolumn{2}{|c|}{ Resultado } & Unidades & Referencia \\
\hline Glucosa & 11.6 & 5.5 & $\mathrm{mmol} / \mathrm{L}$ & $3.4-6.2$ \\
\hline Urea & 11.4 & 12.2 & $\mathrm{mmol} / \mathrm{L}$ & $4.1-7.6$ \\
\hline Creatinina & 152 & 141 & $\mathrm{mmol} / \mathrm{L}$ & $88-156$ \\
\hline Bilirrubina total & 89 & 116.4 & $\mathrm{mmol} / \mathrm{L}$ & $14-54$ \\
\hline B. conjugada & - & 16.4 & $\mathrm{mmol} / \mathrm{L}$ & $6-12$ \\
\hline B. no conjugada & - & 100 & $\mathrm{mmol} / \mathrm{L}$ & $4-44$ \\
\hline AST & 801 & 784 & $U / L$ & $<450$ \\
\hline GLDH & 7 & 14 & $U / L$ & $<11$ \\
\hline GGT & - & 46 & $U / L$ & $<22$ \\
\hline CK & 2211 & 751 & $U / L$ & $<425$ \\
\hline Proteínas totales & 67 & 70 & $\mathrm{~g} / \mathrm{L}$ & $53-71$ \\
\hline Albúmina & 22 & 21 & $\mathrm{~g} / \mathrm{L}$ & $31-39$ \\
\hline Globulinas & 45 & 49 & $g / L$ & $20-35$ \\
\hline Relación A/G & 0.49 & 0.43 & - & $0.89-1.65$ \\
\hline Calcio & 2.79 & 2.64 & $\mathrm{mmol} / \mathrm{L}$ & $2.79-3.22$ \\
\hline Fósforo & 1.92 & 1.27 & $\mathrm{mmol} / \mathrm{L}$ & $0.77-1.67$ \\
\hline Potasio & 4.6 & 3.7 & $\mathrm{mmol} / \mathrm{L}$ & $3.4-5$ \\
\hline Sodio & 130 & 132 & $\mathrm{mmol} / \mathrm{L}$ & $132-141$ \\
\hline Cloro & 96 & 102 & $\mathrm{mmol} / \mathrm{L}$ & $98-105$ \\
\hline Bicarbonato & 12 & 11 & $\mathrm{mmol} / \mathrm{L}$ & $27-34$ \\
\hline Ácidos no volátiles & 27 & 23 & $\mathrm{mmol} / \mathrm{L}$ & $4-13$ \\
\hline DIF & 34 & 30 & $\mathrm{mmol} / \mathrm{L}$ & $30-40$ \\
\hline \multirow[t]{2}{*}{ Osmolalidad } & 274 & 272 & $\mathrm{mOsm} / \mathrm{kg}$ & - \\
\hline & Lipemia 2+ & \multicolumn{3}{|c|}{ Lipemia 3+, Índice ictérico incrementado } \\
\hline
\end{tabular}

Cuadro 3. Resultado del urianálisis (día 1) de la yegua cuarto de milla.

\begin{tabular}{|c|c|}
\hline Examen físico & Examen microscópico \\
\hline $\begin{array}{l}\text { Apariencia: transparente } \\
\text { Color: amarillo rojizo } \\
\text { Densidad: } 1.014\end{array}$ & \multirow{3}{*}{$\begin{array}{l}\text { Eritrocitos: } 0-1 / \text { campo }(400 \times) \\
\text { Leucocitos: } 0-2 / \text { campo }(400 \times) \\
\text { Células transitorias: } 0-2 / \text { campo }(400 \times) \\
\text { Células escamosas: } 0-2 / \text { campo }(400 \times) \\
\text { Cilindros: } 0-1 / \text { campo }(100 \times)\end{array}$} \\
\hline Examen químico & \\
\hline $\begin{array}{l}\mathrm{pH}: 5 \\
\text { Proteínas: trazas g/L } \\
\text { Glucosa: } 0 \mathrm{mmol} / \mathrm{L} \\
\text { Cetonas: } 1+ \\
\text { Bilirrubina: negativo } \\
\text { Urobilinógeno: normal } \\
\text { Sangre/hemoglobina: } 250 \text { eri/ } \mu \mathrm{L}\end{array}$ & \\
\hline
\end{tabular}


incremento de CK y AST por catabolismo muscular; hiperproteinemia por hiperglobulinemia e hipoalbuminemia por inflamación crónica; hiponatremia e hipocloremia por el efecto dilucional de la terapia de líquidos, y acidosis metabólica por acumulación de ácidos (acidosis láctica). En el urianálisis había aciduria marcada por la acidosis metabólica, cetonuria relacionada con un balance energético negativo y hemoglobinuria relacionada con el proceso hemolítico intravascular.

El día 2 se tomó una muestra para la prueba de fijación del complemento para el diagnóstico de piroplasmosis equina (Babesia caballi, Theileria equi) y de inmunodifusión en agar gel para el diagnóstico de anemia infecciosa equina (AIE).

El día 4 se realizó hemograma y bioquímica sérica (Cuadros 7 y 2), en los que resultó anemia severa y reticulocitos de $1.2 \%\left(18 \times 10^{9} / \mathrm{L}\right)$, también hubo incremento de sólidos totales, desviación a la izquierda y monocitosis por inflamación no controlada, crónica, activa.

En la bioquímica sérica había hiperazotemia prerrenal, hiperbilirrubinemia con predominio de la fracción no conjugada por lisis eritrocitaria; incremento de CK y AST por catabolismo muscular; aumento de GLDH y parte del aumento de AST por daño hepatocelular, así como incremento de GGT por colestasis; hipoalbuminemia por hemodilución; hipocalcemia por hipoalbuminemia y acidosis metabólica por acumulación de ácidos (acidosis láctica).

El resultado de las pruebas para la detección de piroplasmosis equina y AIE, fue positivo para esta última. Debido a la infección de la yegua con el virus, así como el riesgo de contagio que representaba para otros caballos, se le practicó la eutanasia mediante sobredosis de barbitúricos y se incineró su cadáver.

\section{Discusión y relevancia clínica}

La anemia hemolítica inmunomediada (AHIM) no es un hallazgo común en el caballo, sin embargo, puede presentarse de manera secundaria a algunas enfermedades neoplásicas (linfoma), a la administración de medicamentos (penicilina) o por procesos infecciosos, tales como la AIE. ${ }^{1}$

En el caso de las AHIM por procesos virales, los eritrocitos están cubiertos con partículas víricas (subunidades de la hemoaglutinina) con la posterior unión de la fracción C3 del complemento, de la lgG o IgM. Los macrófagos presentan receptores hacia estas proteínas, con lo que se inicia la fagocitosis de los eritrocitos marcados y la hemólisis extravascular. Otra vía es la hemólisis intravascular, que se da por la unión de complejos antígeno-anticuerpo presentes en circulación, con lo que se activa la vía clásica del complemento y la lisis osmótica del eritrocito. ${ }^{2}$

En el equino, como en otras especies, los hallazgos útiles para el diagnóstico de AHIM son la aglutinación de eritrocitos y la formación de esferocitos. Los eritrocitos del caballo son pequeños $(5 \mu \mathrm{m})$ en comparación con otras especies y carecen de palidez central evidente, lo que dificulta la detección de esferocitos. ${ }^{3}$ La aglutinación en el extendido sanguíneo de esta paciente y la confirmación con la prueba de aglutinación fueron suficientes elementos para el diagnóstico de AHIM.

En general, los procesos hemolíticos causan una respuesta regenerativa muy marcada y evidente, que se manifiesta en la mayoría de las especies mediante la liberación de reticulocitos a circulación, lo que genera reticulocitosis. ${ }^{4}$ 
En casi todas las especies, los reticulocitos permanecen de dos a tres días en médula ósea antes de salir a circulación, en los caballos la dinámica eritrocitaria es particular debido a que los eritrocitos son liberados solo cuando están completamente maduros ${ }^{4}$ incluso cuando hay aumento en la eritropoyesis, por lo que los reticulocitos se han considerado ausentes de la sangre periférica en esta especie.

Cuando hay un evento que provoque anemia en un equino, no es posible demostrar un proceso regenerativo mediante el análisis de las células en el extendido sanguíneo o con tinciones supravitales como en otras especies, así, cuando en un caballo aumenta la eritropoyesis por la respuesta regenerativa en un proceso hemolítico, es necesaria la evaluación de médula ósea. ${ }^{5}$

Por la dificultad para obtener médula ósea en equinos, se han utilizado otros recursos diagnósticos para determinar el aumento en la producción eritrocitaria, entre estos se encuentran la amplitud de distribución eritrocitaria (RDW, por sus siglas en inglés) y el volumen globular medio (VGM).

El primer término se refiere al coeficiente de variación del volumen de los eritrocitos en una muestra, esto es, un índice de anisocitosis, que muchos analizadores automatizados de hematología calculan y el valor lo reportan en porcentaje. La anisocitosis se da cuando hay una mezcla de eritrocitos maduros de tamaño normal y eritrocitos (reticulocitos) producidos recientemente en médula ósea durante una anemia regenerativa. ${ }^{6}$

El VGM es un indicador del volumen promedio de los eritrocitos en una muestra, de modo que, cuando hay eritrocitos más grandes e inmaduros, se incrementan tanto el promedio como el VGM. Este índice no es muy sensible para la detección de la variación en el tamaño de los eritrocitos ya que se necesita un número grande de eritrocitos inmaduros para elevarlo por encima del límite de referencia. ${ }^{7}$ Tanto el VGM como el RDW pueden mostrar cambios significativos hasta 20 días después de iniciada la anemia, ${ }^{7}$ por lo que la manera más adecuada de detectar un proceso regenerativo es hacer una comparación individual de cada paciente, estableciendo un valor basal con el primer hemograma y haciendo evaluaciones periódicas, en las que es necesario observar un aumento de 10 a $15 \mathrm{fL}$ en el VGM con base en el resultado anterior.

El RDW es un parámetro sensible, ya que con variaciones menores en el tamaño de las células es posible observar un cambio mucho más evidente. Tanto el VGM como el RDW no muestran alteraciones en casos de anemias leves, así que la ausencia de elevación en ambos no descarta el proceso regenerativo. ${ }^{7}$

En la paciente del caso reportado se observó en el primer hemograma VGM de $71 \mathrm{fL}$ y el día 4 el valor fue de $87 \mathrm{fL}$, esto representa un aumento de $16 \mathrm{fL}$, lo que sugiere el incremento de eritrocitos inmaduros en la paciente. En el RDW, no hubo cambios significativos entre el primer y segundo hemograma (25 y $24 \%$ respectivamente); sin embargo, el valor se encontró por encima de los límites de referencia establecidos. Asimismo, la anisocitosis era muy evidente en la evaluación microscópica del frotis sanguíneo (Figura 2).

Los reticulocitos se han considerado ausentes de la circulación sanguínea en equinos; sin embargo, actualmente se sabe que sí están presentes en pequeñas cantidades que son indetectables con métodos y tinciones convencionales. ${ }^{8}$

Se ha desarrollado desde hace algunos años el análisis de muestras con equipos que poseen tecnología láser aunada a la utilización de una tinción fluorescente. Estos equipos detectan eritrocitos inmaduros mediante la coloración del retículo 


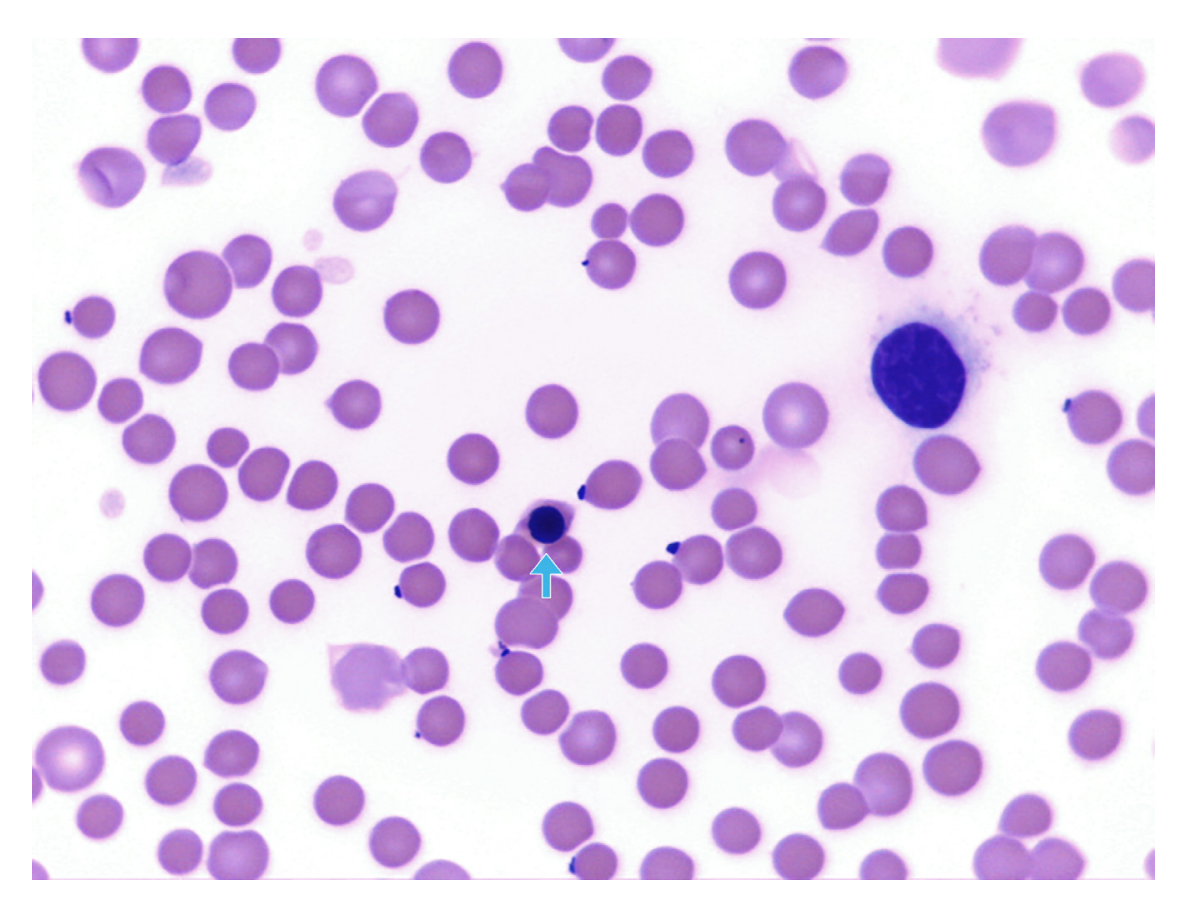

Figura 2. Anisocitosis y eritrocito nucleado $(\uparrow)$ en sangre periférica de la yegua cuarto de milla. Wright 100X.

endoplásmico, incluso pueden definir el grado de madurez de la célula. También pueden detectar reticulocitos con poco ARN, que si se utilizaran tinciones supravitales (nuevo azul de metileno y azul de cresil brillante) no se lograrían teñir y no podrían identificarse. ${ }^{8}$

Teniendo en cuenta lo anterior, el paciente de este caso presentó $1.2 \%$ de reticulocitos $\left(18 \times 10^{9} / \mathrm{L}\right)$ los cuales fueron observados con microscopio óptico de un extendido teñido con nuevo azul de metileno (Figura 3). Un porcentaje de reticulocitos igual al de este paciente (1.2\%) fue reportado en un caballo con anemia hemolítica inmunomediada secundaria a una infección con Clostridium perfringens. ${ }^{8}$ Este paciente, como el de nuestro caso, tenía anemia severa de origen hemolítico y fue posible evidenciar la presencia de reticulocitosis con microscopio óptico.

La anemia infecciosa equina es de las principales causas infecciosas de anemia hemolítica inmunomediada en equinos, en este caso, esta última se confirmó por el resultado de aglutinación positiva.

En términos generales, los reticulocitos son células que siempre se han considerado ausentes de la circulación sanguínea en caballos; sin embargo, se han hecho estudios recientes en los que se ha comprobado su presencia en animales sanos $(1.16-13.10 \times 109 / L)$ y se determinó que los cambios más relevantes solo se ven con anemias severas, ${ }^{9}$ comunes de los procesos hemolíticos.

Finalmente, los índices eritrocíticos, en el que el VGM tuvo un incremento de $16 \mathrm{fL}$ en 4 días y el RDW estaba por encima del intervalo de referencia, sugieren que la paciente de este caso clínico tuvo un incremento en la respuesta eritropoyética. El hecho de haber observado reticulocitos con una técnica tan poco sensible como el uso de nuevo azul de metileno, es un hallazgo relevante. 


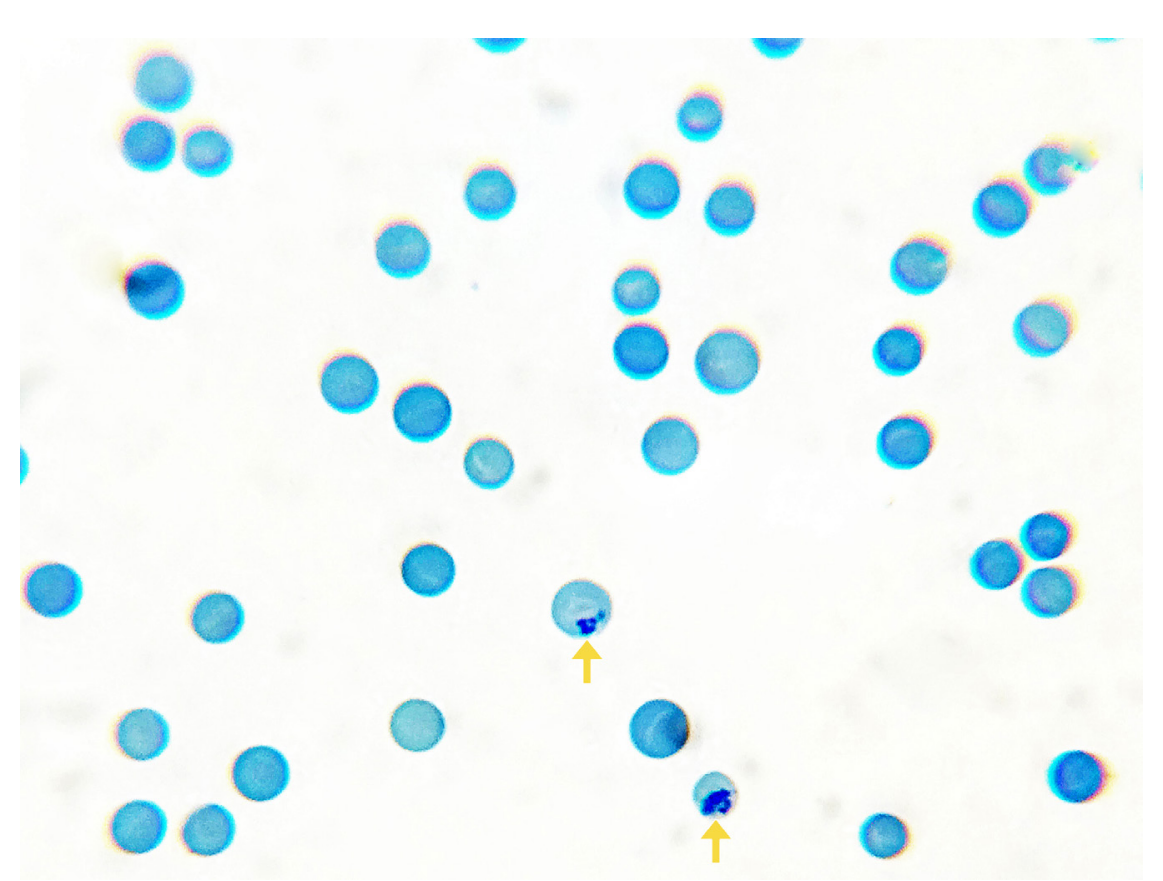

Figura 3. Reticulocitos $(\uparrow)$ en sangre periférica de yegua cuarto de milla. Nuevo azul de metileno 100X.

\section{Financiamiento}

Todos los estudios de patología clínica y del diagnóstico de enfermedades infecciosas fueron pagados por el propietario del paciente.

\section{Agradecimientos}

Al personal médico del Hospital para Équidos del Departamento de Medicina, Cirugía y Zootecnia para Équidos de la FMVZ-UNAM por facilitar el seguimiento de este caso.

\section{Conflictos de interés}

Los autores declaran que no tienen ningún conflicto de interés.

\section{Contribución de los autores}

ALM revisó y corrigió el manuscrito. MGO diagnosticó e interpretó la patología clínica, además revisó y corrigió el manuscrito. YLG fue el clínico a cargo del paciente, además revisó y corrigió el manuscrito. DEA interpretó la patología clínica y redactó el manuscrito.

\section{Referencias}

1. Smith BP. Large animal internal medicine: diseases of horses, cattle, sheep, and goats. 4a ed. California (US): Mosby Elsevier; 2009.

2. Mealey RH. Equine infectious diseases. 2a ed. Missouri (US): Elsevier Health Sciences; 2013.

3. Taylor FG, Brazil T, Hillyer MH. Diagnostic techniques in equine medicine. $2 a$ ed. Bristol (GB): Saunders Elsevier; 2010.

4. Latimer KS. Duncan and Prasse's veterinary laboratory medicine: clinical pathology. 5a ed. lowa (US): Wiley-Blackwell; 2011. 
5. Lording PM. Erythrocytes. Veterinary clinics of North America: equine practice [internet] 2008;24(2):225-37. Disponible en: https://www.sciencedirect.com/ journal/veterinary-clinics-of-north-america-equine-practice/vol/24/issue/2 [citado 10 junio 2019].

6. Walton RM. Equine clinical pathology. lowa (US): Wiley-Blackwell; 2014.

7. Hinchcliff K, Kaneps A and Geor R. Equine sports medicine \& surgery: basic and clinical sciences of the equine athlete. 2a ed. Londres (GB): Saunders Elsevier; 2013.

8. Weiss DJ, Moritz A. Equine immune-mediated hemolytic anemia associated with Clostridium perfringens infection. Veterinary clinical pathology [internet] 2003;32(1):22-6. Disponible en: https://www.ncbi.nlm.nih.gov/ pubmed/12655485 [citado 10 junio 2019].

9. Balan M, McCullough M, O'Brien PJ. Equine blood reticulocytes: reference intervals, physiological and pathological changes. Comparative Clinical Pathology [internet] 2018;1-10. Disponible en: https://www.researchgate.net/publication/327723325_Equine_blood_reticulocytes_reference_intervals_physiological_and_pathological_changes [citado 10 de junio 2019]. 